\title{
Synaptic Specificity in Frog Sympathetic Ganglia During Reinnervation, Sprouting, and Embryonic Development
}

\author{
Daniel H. Feldman \\ Neuroscience Graduate Program, Department of Physiology, University of California, School of Medicine, San Francisco, \\ California 94143
}

$B$ cells and $\mathbf{C}$ cells in frog lumbar sympathetic ganglia are specifically innervated by preganglionic $B$ fibers and $\mathrm{C}$ fibers, respectively. To explore the mechanisms underlying the formation of these specific synapses, electrophysiological studies were made of sprouting and regenerating synaptic connections following interruption of the preganglionic pathways. Studies were also made of developing connections in tadpole ganglia.

After partial denervation (by selective interruption of $B$ fibers), the $C$ fibers sprouted and innervated $B$ cells. When $B$ fibers regenerated, they reinnervated $B$ cells only, and within several weeks, $C$ fiber synapses on $B$ cells were no longer found.

After complete denervation (by interruption of both B and C fibers) specific synaptic connections were eventually restored. At least 2 experimentally separable processes underlie this specificity: First, there is a preference for appropriate connections from the outset of reinnervation, seen even in the absence of competition between the 2 groups of preganglionic fibers. Despite this preference, however, some inappropriate synapses are formed. Second, those inappropriate synapses that do arise are eliminated when appropriate synapses are allowed to reform, as a result of competitive interactions between the 2 preganglionic fiber groups.

In normally developing tadpole ganglia, $B$ and $C$ cells were not readily distinguishable. The great majority of tadpole neurons were found to be innervated exclusively by either $\mathrm{B}$ or $\mathrm{C}$ fibers. Some neurons were innervated by both preganglionic fiber groups, a situation virtually never found in adult ganglia. It thus appears that in normal development, as in reinnervation, innervation is by and large selective; inappropriate synapses may form, but they are eliminated during maturation, presumably through competitive interactions.

Although substantial progress has been made in recent years, the mechanisms that underlie the formation of specific synaptic connections in the nervous system are not fully understood. One

\footnotetext{
Received Feb. 16, 1988; accepted Apr. 20, 1988.

I wish to thank Michael Dennis, in whose laboratory this work was carried out, for advice and support throughout the execution of this project. I am grateful to Roger Nicoll for his enthusiastic encouragement and advice, and to Zach Hall, Dale Purves, Joshua Sanes, and David Van Essen for helpful suggestions pertaining to the manuscript. Supported by NIH Grant NS10792 to Michael Dennis. The author was a National Science Foundation Predoctoral Fellow.

Correspondence should be addressed to Dr. Daniel H. Feldman at his present address: Department of Biology, University of Utah, Salt Lake City, UT 84112. Copyright (C) 1988 Society for Neuroscience $0270-6474 / 88 / 114367-12 \$ 02.00 / 0$
}

impediment to progress in this area has been the difficulty of performing physiological studies on embryonic tissue. The study of regenerating synaptic connections in mature animals has yielded considerable insight into the nature of synaptic specificity in a variety of systems, thereby supplementing embryonic studies.

Here I describe studies carried out both in mature and developing animals intended to explore the nature of synaptic specificity and plasticity in frog and tadpole lumbar sympathetic ganglia. The frog ganglia are advantageous for examination of the cellular mechanisms that underlie synaptic specificity because of their simplicity, accessibility, and manipulability: there are 2 types of principal neurons (B cells and $C$ cells) that receive input from distinct populations (B fibers and $C$ fibers, respectively) of preganglionic fibers (Nishi et al., 1965). The 2 preganglionic fiber types enter the sympathetic trunk at different segmental levels (Skok, 1965; Libet et al., 1968; Francini and Urbani, 1973), and thus they may be independently stimulated or experimentally manipulated. The 2 cell populations are interspersed within the ganglia, yet in mature frogs each is exclusively innervated by its complementary preganglionic fiber type. In tadpole ganglia, little is known about ganglion cells or their innervation. The situation in adult ganglia is comparable to that existing in many areas of the CNS, where the specific targets of distinct afferent fiber populations are interspersed. A central problem in developmental neurobiology is how such systems develop appropriate synaptic connections.

Three related studies are presented. Experiments with adult frogs involved selective surgical lesions of preganglionic fibers and subsequent intracellular recording from ganglion cells in an isolated preparation. In the first group of experiments, ganglia of adult frogs were partially denervated by selective elimination of the preganglionic B fibcrs, thus dcpriving B cells of synaptic input. During the subsequent several weeks, synaptic input to $B$ cells by the intact $C$ fibers was observed: $C$ fibers had sprouted and innervated the denervated $B$ cells. These sprouted synapses withdrew upon regeneration of the $B$ fibers.

In a second group of experiments, adult ganglia were completely denervated, and the specificity of regenerating synapses was studied. The ganglion cells were found to be selectively reinnervated. This specificity arises from selective forces manifest in 2 ways. First, there is some selectivity in the initial synapses formed, even in the absence of competition between preganglionic fibers. Second, as a result of competitive interactions between preganglionic fibers, inappropriate synapses are selectively eliminated.

Finally, an initial study of normally developing tadpole ganglia was undertaken to explore the role of competition in the 


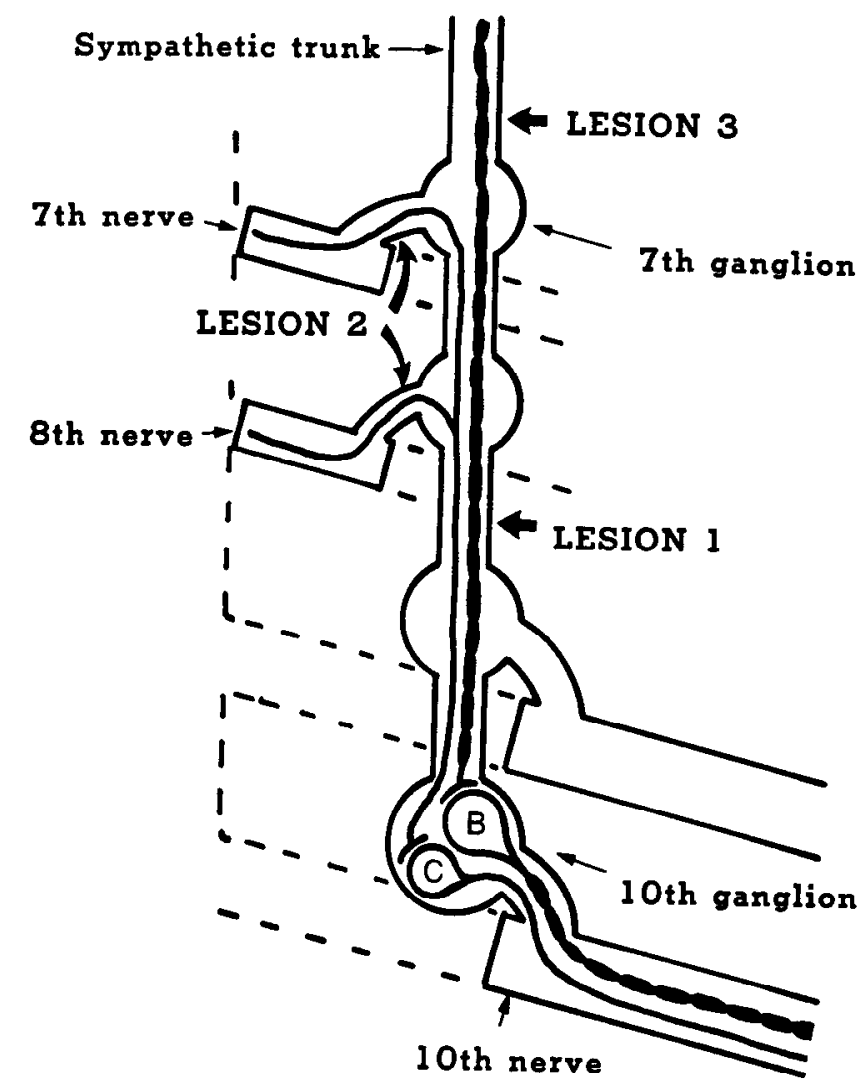

Figure 1. Schematic diagram of the lumbar sympathetic chain with associated spinal nerves. The myelinated B fiber and B cell axon populations are represented by dashed lines, and the nonmyelinated $\mathrm{C}$ fiber and $C$ cell axon populations are represented by continuous lines. The innervation pattern for $B$ and $C$ cells in the 9th ganglion is identical to that shown for the 10th. Preganglionic B fibers are stimulated in the 7 th and 8th nerves. The postganglionic axons of $B$ and $C$ cells are antidromically stimulated in the 10 th (or 9 th) nerve. The sites of lesions for various experiments are illustrated here, and are specified in the text.

formation of specific synaptic connections. Evidence was obtained suggesting that specific innervation in the developing ganglion comes about through mechanisms similar to those found during regeneration.

Some of these results have been reported in abstract (Feldman, 1979, 1980).

\section{Materials and Methods}

The numbering system for ganglia and spinal nerves used here is that of Ecker and Weidersheim (Gaupp, 1899), in which the sciatic plexus is composed of nerves 8,9 , and 10 . A small 11 th nerve is occasionally present. Ganglia are numbered according to the spinal nerves with which they connect via rami communicantes.

Two principal neuronal types have been distinguished in the 9th and 10 th sympathetic ganglia of anuran amphibia. In the toad, B cells have myelinated axons with conduction velocities of $1.2-8 \mathrm{~m} / \mathrm{sec}$, whereas $C$ cells have nonmyelinated axons, conducting at $0.2-0.8 \mathrm{~m} / \mathrm{sec}$. B cells are innervated by myelinated preganglionic $B$ fibers conducting at 2$13 \mathrm{~m} / \mathrm{sec}$, whereas $C$ cells are innervated by nonmyelinated preganglionic C fibers conducting at $0.2-0.4 \mathrm{~m} / \mathrm{sec}$ (Nishi et al., 1965). In frogs (but not in the toad), the 2 groups of preganglionic fibers enter the sympathetic trunk at different segmental levels: $B$ fibers enter anterior to the 7th segmental ganglion, whereas $C$ fibers enter at the 7 th and 8th segmental levels (Skok, 1965; Libet et al., 1968; Francini and Urbani, 1973). Thus, as illustrated in Figure 1, the 2 preganglionic fiber groups may be independently stimulated or surgically interrupted. In the first section of Results, I verify that, for the most part, these features also apply in Rana pipiens.

Denervation. Frogs were anesthetized by immersion in a $1.3 \mathrm{gm} / \mathrm{liter}$ solution of tricaine methanesulfonate (Sigma). The skin and muscle wall were cut 3-4 mm ventral to the pelvic protuberance, and the peritoneum was pulled ventrally to expose the sympathetic trunk and spinal nerves. The principal landmark used to determine the proper site for lesion was the sciatic plexus, composed of nerves $8-10$. The lesion sites for various experiments are detailed in the appropriate sections of Results. For crush lesions, the nerve trunk was pinched with a pair of fine forceps several times. In some experiments (see Results), the nerve trunk was intentionally transected.

After denervation, the muscle wall and skin were independently sutured. The animals were revived and were maintained in tanks where they had access to both a dry platform (air temp. $20-22^{\circ} \mathrm{C}$ ) and a reservoir of running tap water $\left(14-18^{\circ} \mathrm{C}\right)$. They were fed weekly with either homogenized beef liver or live crickets.

After intervals of 1-22 weeks, the innervation of ganglion cells was studied in the isolated preparation (see below). Twenty to 35 cells were sampled in a given preparation, usually at least 10 each of $B$ and $C$ cells. The ability to anticipate a cell's type by its diameter (see Results) made it possible to select for B or C cells. The results from ganglia examined at particular postoperative intervals were pooled to obtain information about the time course of innervation.

Physiological techniques. The caudal portion of the sympathetic chain, including ganglia 7-10, the proximal (preganglionic) segments of spinal nerves 7 and 8 , and the distal (postganglionic) segments of spinal nerves 9 and 10 , was dissected out and pinned in a chamber with a bottom consisting of a Sylgard-coated glass coverslip. Preganglionic B and C fiber populations were separately stimulated, as diagrammed in Figure 1 , with suction electrodes applied to the sympathetic trunk anterior to the 7 th ganglion (B fibers) and to spinal nerves 7 and 8 ( $C$ fibers). A suction electrode was also applied to the 10 th (or occasionally 9 th) nerve for antidromic stimulation of postganglionic axons in the 10th (9th) ganglion. (In some preparations, the 9 th and 10th ganglia fuse to form a single compound ganglion; in these, antidromic stimulation was applied to the sciatic nerve just distal to the point of anastomosis of the 9 th and 10th nerves.) The postganglionic suction electrode was also used for extracellular recording of the synaptically evoked postganglionic compound action potentials. This provided a convenient means of monitoring the overall health of a preparation during an experiment and of making a crude assessment of the extent of reinnervation of a ganglion.

Preganglionic and postganglionic axons were stimulated with $0.5 \mathrm{msec}$ pulses at $<1 \mathrm{pulse} / \mathrm{sec}$. Stimulus intensities were generally in the range of 0.3-2.0 V for B fibers and $\mathrm{B}$ cell axons, and 1-5 V for $\mathrm{C}$ fibers and $\mathrm{C}$ cell axons.

Intracellular recording was carried out under direct observation through a $40 \times$ water-immersion objective, at a total magnification of $500 \times$ using Zeiss-Nomarski interference contrast optics. The resolution provided by this optical system facilitated successful ganglion cell recordings, particularly in the case of $\mathrm{C}$ cells which, due to their size, are difficult to penetrate successfully. Ganglia were studied at room temperature $\left(20-22^{\circ} \mathrm{C}\right)$ perfused in Ringer's solution of the following composition (in $\mathrm{mM}$ ): $\mathrm{NaCl}, 120 ; \mathrm{KCl}, 2 ; \mathrm{CaCl}_{2}, 3.6$; glucose, 10 ; HEPES buffer, 4 ( $\mathrm{pH} \mathrm{7.3)}$. The calcium concentration used was twice that of normal frog Ringer's, serving to increase the size of synaptic potentials and to increase the stability of intracellular recordings. Micropipettes for intracellular recording were pulled from thin-walled capillary tubing (Federick Haer and Co., Brunswick, ME) on a Brown-Flaming design puller (Brown and Flaming, 1977). Electrodes were filled with 4 м potassium acetate and had resistances of 30-50 M $\Omega$. Conventional methods for single-electrode recording and current injection were used.

Synaptic input was categorized on the basis of its anatomical source; thus, when stimulation of the sympathetic trunk anterior to the 7 th ganglion caused a synaptic response, the cell was considered to receive $\mathrm{B}$ fiber input, and a response due to stimulation of the 7 th or 8 th nerves was taken to indicate $C$ fiber input. The stimulating current was gradually increased between pulses to search for increments in amplitude of the synaptic response resulting from excitation of additional innervating fibers. Synaptic responses elicited by stimulation of low-threshold preganglionic inputs sometimes excited action potentials, which obscured additional synaptic steps elicited at higher intensities of preganglionic stimulation. Such masking was avoided by timing the synaptic response so that it fell during the refractory period following a spike 
elicited directly by a depolarizing current pulse (Purves, 1975). Some neurons appeared to receive both a $\mathrm{B}$ fiber and a $\mathrm{C}$ fiber input, with synaptic potentials of each having similar size and waveform. In such cases, the possibility that branches of one axon were present in both preganglionic roots was checked by means of a collision test. Only the nicotinic fast excitatory postsynaptic potentials (Kuba and Koketsu, 1978) were examined in this study.

Ganglionic neurons were classified from the latency of antidromic action potential invasion in the cell body, which proved to be a reliable means of distinguishing $B$ and $C$ cells in both normal and reinnervated ganglia (see Results). At the end of an experiment, the ganglion from which intracellular recordings had been made was drawn into a suction electrode, and the antidromically propagated compound action potentials were recorded extracellularly. Two or three populations (see Results on the intermediate, or slow-B, population) of axons were resolved in this way. The highest threshold, slowest wave was due to the $C$ cell axons, and its latency was taken as a minimum value for distinguishing $\mathrm{C}$ cells by intracellular determination of antidromic latency. The latencies of fast-B and, when present, slow-B waves, were likewise used to identify the fast-B and slow-B cells recorded intracellularly. Thus, each intracellularly studied cell was assigned to a class by comparison of its antidromic latency with the latencies of extracellularly recorded compound antidromic action potentials. In this way, variability among preparations due to nerve length and temperature was effectively normalized. Axonal conduction velocities were estimated from the latency of responses and the approximate conduction distances.

Tadpoles. Rana catesbiana tadpoles were staged according to Taylor and Kollros (1946), a staging scheme developed for $R$. pipiens larvae; the development of $R$. catesbiana conforms adcquatcly. The stagc of each specimen could be defined precisely, i.e., within narrow limits spanning 2 stages. Most animals studied were at stages $17-18$, by which time the hindlimb (a major target of the neurons of the 9th and 10th ganglia) is well developed and has become functional. Innervation of the 9 th and 10th sympathetic ganglia has begun by this stage (Dunn and Marshall, 1983). Some preparations were studied as early as stages 14-15, and some at stages 21-22, during the period of rapid metamorphosis. Postmetamorphic juvenile frogs were also studied.

Tadpoles were anesthetized in a $1 \mathrm{gm}$ /liter tricaine methanesulfonate solution for $5 \mathrm{~min}$. A ventral incision was made, and the heart was exposed. Animals were perfused through the heart with a Ringer's solution as above, except containing $5 \mathrm{~mm} \mathrm{CaCl}_{2}$. The sympathetic chain including ganglia 6-9 (recordings were made from the 9th rather than the 10th ganglion because at stages 17-18, there appeared to be little or no connection between the 10th ganglion and the 10th nerve), the proximal segments of the 7th and 8th spinal nerves, and the distal segment of the 9 th nerve were dissected out, with care laken to avoid stretching the delicate rami communicantes. Physiological methods were essentially as described for adult preparations. Preganglionic trunks were stimulated at low frequencies (not exceeding $0.5 \mathrm{sec}^{-1}$ ) to avoid fatiguing the developing synapses, which often transmitted with small, fluctuating postsynaptic potentials indicative of low quantal content.

\section{Results}

\section{Normal ganglia}

Neurons in normal ganglia could usually be classified as B or C cells by means of their antidromic propagation rate and their synaptic input, as is so in the toad Bufo vulgaris japonica (Nishi et al., 1965) and in other species of frog, Rana catesbiana (Libet et al., 1968) and $R$. esculenta (Skok, 1965; Francini and Urbani, 1973). In some ganglia a class of neurons not previously recognized in the other anuran species could be distinguished; these I will refer to as slow-B cells, in accordance with the nomenclature recently introduced by Dodd and Horn (1983), who independently described this class of neurons in $R$. catesbiana. My findings agree in most respects with those of Dodd and Horn. In $R$. pipiens, these slow-B cells were characterized by axonal conduction velocities, excitation thresholds, and soma diameters intermediate between those of fast- $\mathrm{B}$ and $\mathrm{C}$ cell populations (see below). The synaptic inputs to slow-B cells were B fibers, as judged by their entrance into the sympathetic trunk anterior
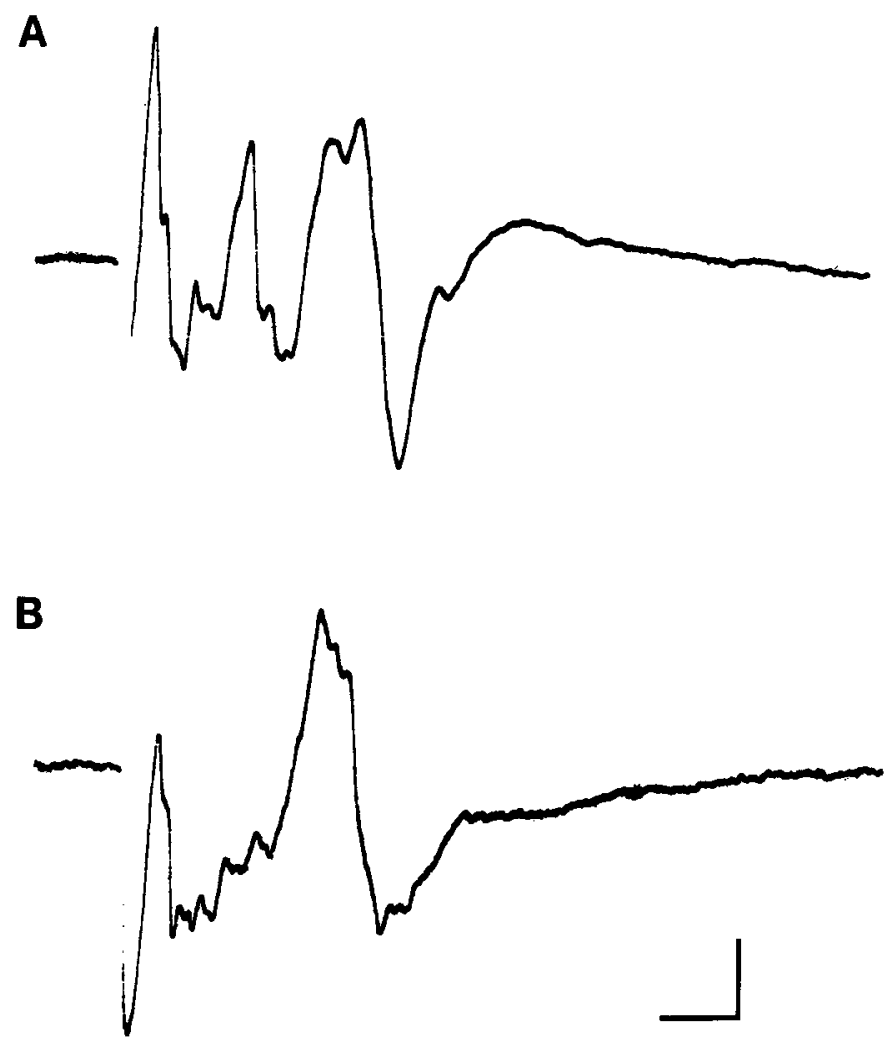

Figure 2. Postganglionic fiber groups revealed by antidromic compound action potentials. Compound action potentials $A$ and $B$, evoked by antidromic stimulation of the 10th nerves, were recorded from the 10th ganglia of 2 different preparations. In $A$, three major populations of postganglionic axons were present, corresponding to fast- $\mathrm{B}$, slow-B, and $C$ groups. In $B$, mainly fast- $B$ and $C$ cell axons were present. $C a l-$ ibration bars: horizontal, $10 \mathrm{msec}$; vertical, $20 \mu \mathrm{V}$. Traces have been retouched.

to the 7th ganglion, and the latencies of orthodromic activation, which were similar to those of fast-B cells. Evidence for these 3 classes of ganglion cell can be seen in Figure $2 A$, which is a recording made from the surface of the 10th ganglion of one preparation following antidromic stimulation of the nerve approximately $6 \mathrm{~mm}$ away. Three well-resolved potential peaks are visible, which are correlated with approximate conduction velocities of $1.5,0.4$, and $0.2 \mathrm{~m} / \mathrm{sec}$. The first peak results from activity in the axons of fast-B cells. The conduction velocities of the second and third peaks would classify them as C fibers; however, I distinguish them because of their different conduction velocities, and their different sources of innervation.

The results of intracellular recording from cells in normal ganglia are shown in Figure $3 A$, where the number of cells (ordinate) with given latencies of antidromic spike invasion (abscissa) are indicated, according to the type of innervation they receive. The histogram includes data from all normal preparations studied, without correction for nerve length or other sources of variability of antidromic latency. Cells appear to fall into 3 populations. The fastest conducting group and the intermediate group are innervated by $B$ fibers, found in the sympathetic trunk anterior to the 7th ganglion, whereas cells in the slowest conducting group are innervated by $\mathrm{C}$ fibers, entering via the 7 th or 8 th spinal nerves. Of the neurons innervated by B fibers, for the sake of analysis I have arbitrarily taken those with latencies of 6 msec or less (to the left of the arrows in Fig. 


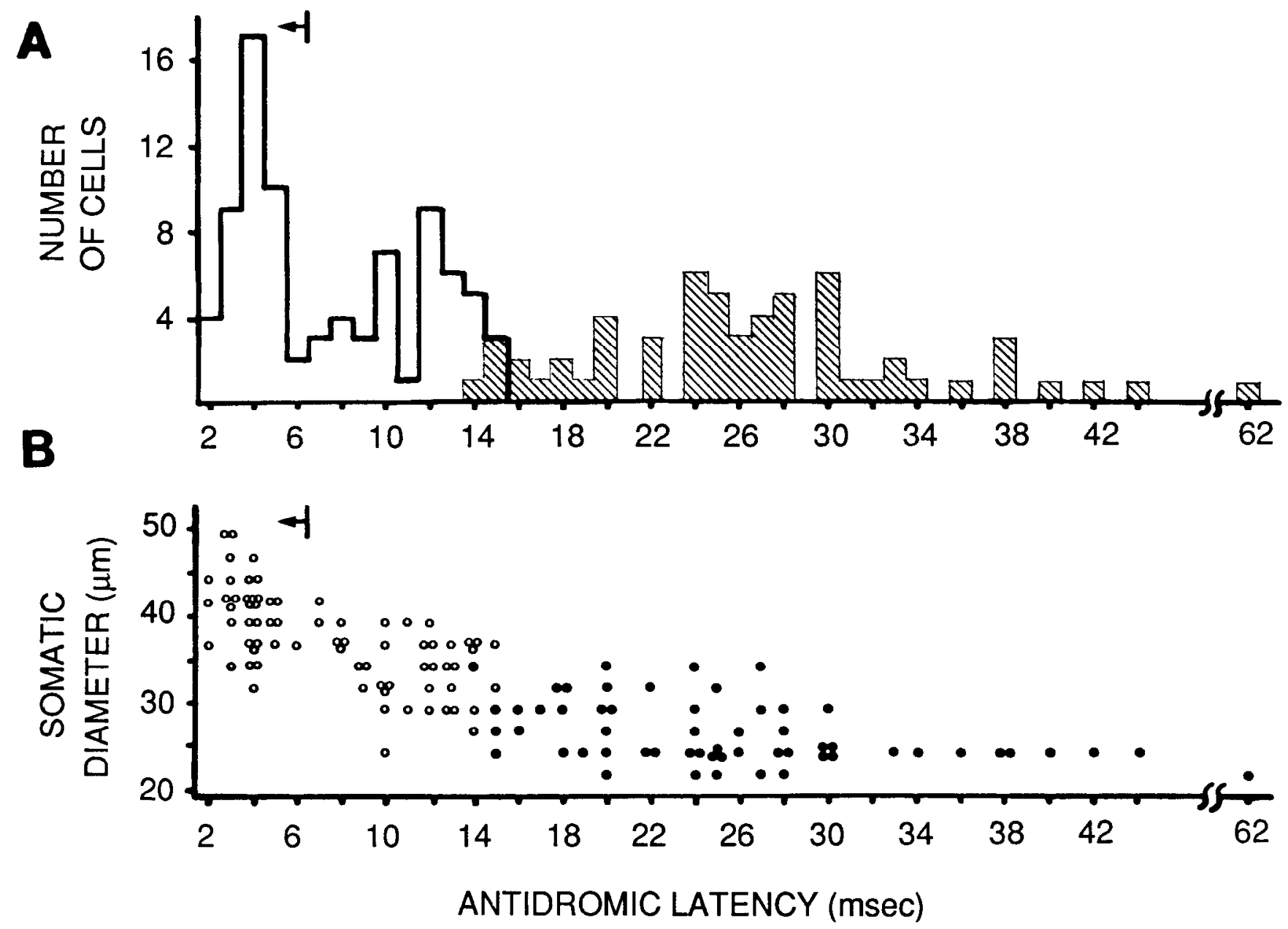

Figure 3. Properties of neurons in normal ganglia. A, Histogram of antidromic action potential invasion latencies for neurons in normal ganglia, tabulated according to source of synaptic input. Neurons in which synaptic potentials could be elicited by stimulation of the sympathetic trunk (i.e., innervated by B fibers) are indicated by open bars; those in which synaptic potentials could be elicited by stimulation of the 7th or 8th nerves (i.e., innervated by $\mathrm{C}$ fibers) are indicated by shaded bars. When the data for all normal ganglia are thus pooled, these 2 populations overlap slightly in antidromic latency. Within individual ganglia, however, such overlap was never observed: Cells innervated by $C$ fibers always had longer latencies than those innervated by B fibers. The arrow marks the arbitrarily defined cutoff for fast-B cells, used for calculation of antidromic conduction velocity. Cells innervated by B fibers, but to the right of the arrow, were regarded to be slow-B cells. $B$, Scatter plot of cell body diameters plotted as a function of antidromic latency. Neurons with B fiber input are plotted with open circles; neurons with C fiber input are plotted with closed circles. Measurements of the living neurons were made with an eyepiece micrometer when antidromic latency was determined. For oblong-shaped neurons, the measurements of long and short axes were averaged.

3, $A$ and $B$ ) as fast-B cells and those with latencies longer than $6 \mathrm{msec}$ as slow-B cells. All the cells innervated by $C$ fibers are considered to be $C$ cells. Assuming an average conduction distance of $5 \mathrm{~mm}$, approximate mean conduction velocities $( \pm \mathrm{SD})$ for these populations are as follows: fast-B cells, $1.4 \pm 0.4 \mathrm{~m} / \mathrm{sec}$; slow-B cells, $0.46 \pm 0.11 \mathrm{~m} / \mathrm{sec}$; C cells, $0.2 \pm 0.06 \mathrm{~m} / \mathrm{sec}$.

The cells of the 3 populations differed in size, in accordance with their conduction velocities, as shown in Figure $3 B$. The soma diameters of the cells identified as members of each class were as follows (means $\pm \mathrm{SD}$, in $\mu \mathrm{m}$ ): fast-B cells, $39.7 \pm 3.8$; slow-B cells, $32.6 \pm 3.6$; C cells, $26.2 \pm 3.4$. These differences in size between the 3 cell types facilitated selection of cells of any desired class for intracellular recording. Apparently in $R$. catesbiana slow-B cells do not differ significantly in size from fast-B cells (Dodd and Horn, 1983).

The relative numbers of cells in the 3 populations, judged by the amplitudes of antidromic potentials recorded extracellularly and the antidromic latencies recorded intracellularly, varied among different preparations. The slow-B population was the most variable. In some ganglia, no slow-B cells were found by intracellular recording, and few or none were detected by extracellular recording of the antidromic compound action potentials, which showed only $B$ and $C$ volleys. Figure $2 B$ is an example taken from one such ganglion.

\section{Experimental ganglia}

Neuronal populations

As described above, in normal ganglia, $B$ and $C$ cells are readily distinguishable by their conduction velocities and their preganglionic innervation. Somatic diameters are also useful for distinguishing cell types. However, in denervated and reinnervated ganglia, the type of preganglionic innervation to the neurons was itself the subject of investigation and could not be used as an indication of postganglionic cell type. Cells were therefore classified by their conduction rates and diameters. These remained reliable criteria, as demonstrated by the fact that neu- 
rons in experimental ganglia, regardless of the type of lesion or the postoperative survival period, were similar to neurons in normal ganglia with respect to conduction velocities and somatic diameters. This was true also of several ganglia in which preganglionic input was kept away for several weeks by repeated resection of all inputs. The relative numbers of each cell type populating the ganglia were comparable (though variable) in both experimental and normal animals, as judged by the amplitudes of compound action potentials antidromically propagated into the ganglia.

Because of possible ambiguity in distinguishing slow-B cells from $C$ cells in experimental ganglia (despite their different conduction velocities), no attempt was made to study slow-B cells systematically; the studies described below focus on fast-B cells and $C$ cells. As described in Materials and Methods, $C$ cells were identified by virtue of their antidromic latency exceeding the value for the $C$ population as a whole, determined by extracellular recording from ganglia at the conclusion of each recording session.

\section{Sprouting}

To examine the plasticity of synaptic connections in the ganglia of mature frogs, B fibers were selectively interrupted by cutting the sympathetic trunk connective between the 6 th and 7 th ganglia. After various recovery periods, a "sprouted" connection was identified when a B cell responded with a synaptic potential to stimulation of the 7 th or 8th nerves (which carry only $\mathrm{C}$ fibers).

In 6 preparations in which $\mathrm{B}$ fiber input had been removed $1.5-5$ weeks prior to recording, $49 \%$ of the B cells ( 33 of 68 ) received synaptic input from one or more $C$ fibers, as in the example of Figure 4. The $C$ cells in these ganglia appeared normally innervated. The synapses from sprouted $C$ fibers onto $B$ cells usually generated rapidly rising synaptic potentials, often of sufficient amplitude to fire the postsynaptic cell after a single orthodromic impulse. Some sprouted inputs generated more slowly rising potentials, perhaps because those synapses were on the axon at some distance from the cell body.

In preparations examined 6-21 weeks after partial denervation, continuity of the sympathetic trunk was usually restored, although the site of the original lesion could often be seen under the dissecting microscope. In these preparations, the B fiber input to ganglionic neurons was determined by stimulating the trunk anterior to the 7th ganglion but posterior to the site of the original lesion. Four of these preparations with regenerated trunks were examined. No $C$ fiber inputs to $B$ cells were detected, and $92 \%$ of the B cells ( 35 of 38 ) were reinnervated by B fibers. Surprisingly, none of $22 \mathrm{C}$ cells examined in these ganglia was innervated by the regenerated $B$ fibers $-C$ cells were innervated by $\mathrm{C}$ fibers exclusively.

These results indicate that when B cells are denervated by selectively removing all $\mathrm{B}$ fiber input, intact $\mathrm{C}$ fibers are induced to sprout and form synapses with the denervated neurons. When the B fibers return, they reinnervate B cells only, and sprouted $\mathrm{C}$ fiber synapses are no longer detectable.

\section{Reinnervation}

To study the specificity of reinnervation of completely denervated ganglia, both $\mathrm{B}$ and $\mathrm{C}$ fiber inputs were interrupted by crushing the sympathetic trunk between the 8th and 9th ganglia (Lesion 1 in Fig. 1). Forty-six such preparations were examined at various intervals (2-22 weeks) after the denervation. During

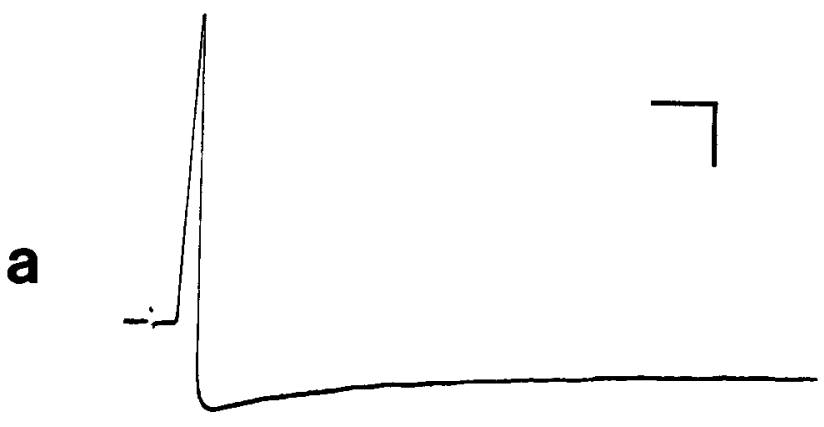

b
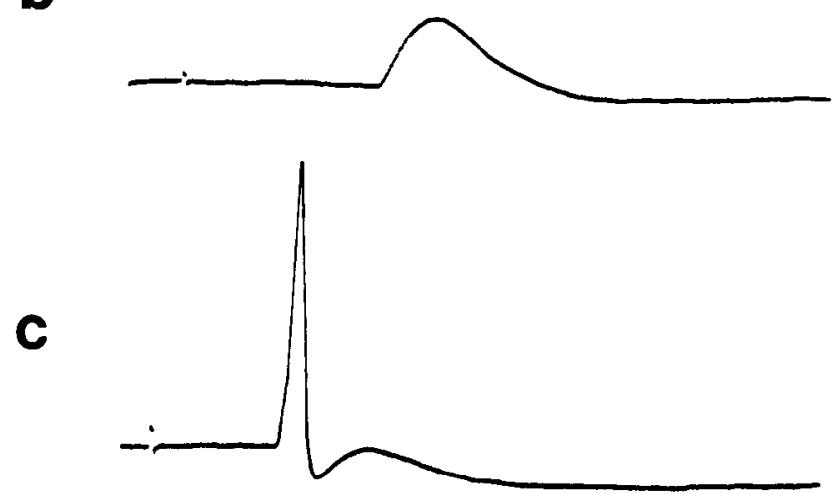

Figure 4. Physiological evidence of "sprouted" synapses. A, Antidromic action potential from a $B$ cell that received at least 2 sprouted $\mathrm{C}$ fiber synapses. The short latency is typical of $\mathrm{B}$ cells. $B$ and $C$, Synaptic potentials elicited in this cell upon stimulation of $C$ fibers in the 7 th $(B)$ and 8 th $(C)$ nerves. The relatively long latencies of these responses are typical for $C$ fibers. The response shown in $(C)$ was of sufficient amplitude to elicit an action potential. Calibration bars: horizontal, 10 msec; vertical, $20 \mathrm{mV}$. Action potentials retouched.

this period, $86 \%$ ( 279 of 323 ) of the cells identified as fast-B cells were appropriately reinnervated by $B$ fibers, often by 2 or 3 different ones. Innervation of fast- $B$ cells by $C$ fibers was rare $(\sim 2 \%)$, and most of the fast-B cells with $C$ fiber input simultaneously received $B$ fiber input. Thus, fast-B cells were appropriately reinnervated from the outset, and remained so throughout the postoperative period studied.

Although the reinnervation of slow-B cells was not systematically studied, the results were essentially the same as for fastB cells: slow-B cells were reinnervated primarily by $B$ fibers.

In contrast to the initial and persistent appropriate reinnervation of $B$ cells, the nature of the synaptic input to $C$ cells varied with the survival period. As shown in Figure 5 (filled bars), a large fraction of $\mathrm{C}$ cells examined during the first 5 weeks of reinnervation were reinnervated by $B$ fibers, often by 2 or more. The frequency of such inappropriate innervation dropped off sharply during the 6 th week, declining to less than $10 \%$ subsequently.

$C$ fiber input to $C$ cells returned during the first several weeks of reinnervation. As shown in Figure 5 (open bars), appropriate input is restored to $70 \%$ of $\mathrm{C}$ cells by the 4 th week, prior to the time when inappropriate input begins to disappear. $\mathrm{C}$ cells frequently received both $B$ and $C$ fiber input during weeks 2-5. Figure 6 shows responses from a cell that received both appropriate and inappropriate inputs. 
Figure 5. Time courses of reinnervation of $\mathrm{C}$ cells in denervated ganglia by either B fibers (solid bars) or C fibers (open bars). Each bar represents the pooled data from several preparations examined during the given postoperalive weeks. The shaded bar indicates the innervation of $C$ cells by $B$ fibers in ganglia in which the normal $C$ fiber input was kept away by cutting the rami communicantes connecting nerves 7 and 8 to the sympathetic trunk (Lesion $1+$ Lesion 2); the results depicted by solid and shaded bars were from ganglia denervated by a single crush lesion (Lesion 1 in Fig. 1). In most ganglia studied from 6-22 weeks after denervation, the contribution of $\mathrm{C}$ fibers from the 7 th nerve was neglected; thus, values indicated by open bars for these time bins represent a lower limit to the percentage of $\mathrm{C}$ cells reinnervated by $\mathrm{C}$ fibers. The 7 th nerve typically innervates $20-30 \%$ of the $\mathrm{C}$ cells in a normal 10th ganglion.

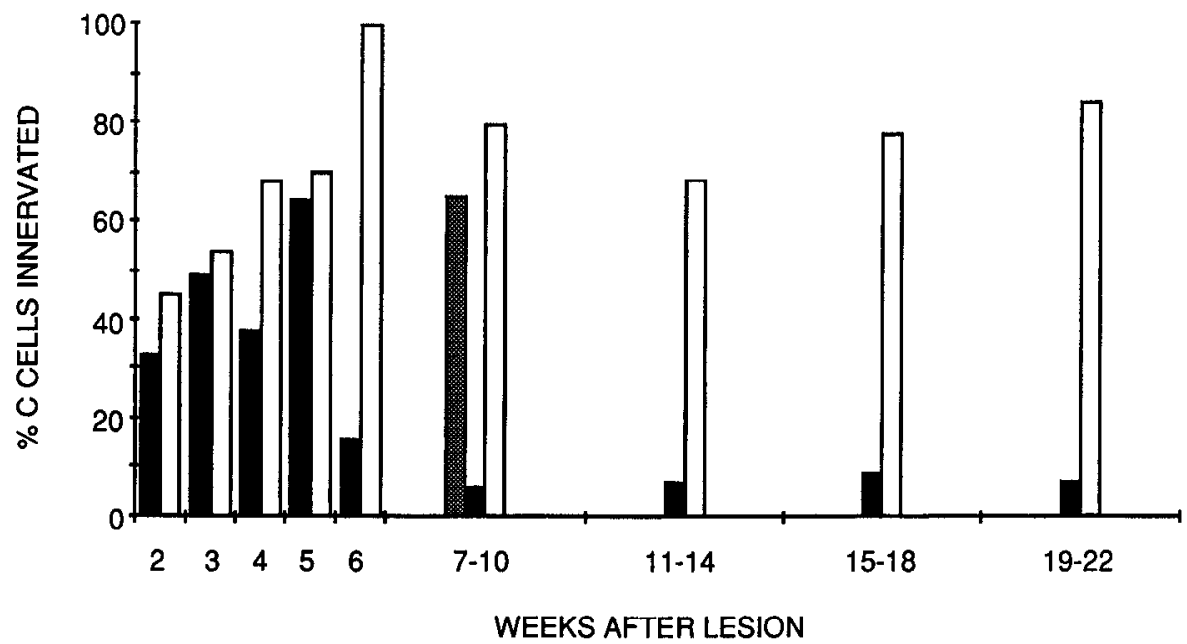

The inappropriate synapses often gave rise to synaptic potentials of sufficient amplitude to fire the $\mathrm{C}$ cells. Though not rigorously studied, the rise times and durations of potentials elicited by inappropriate synapses were comparable to those of regenerated appropriate synapses. For cells simultaneously innervated with both fiber types, there was no consistent trend as to which type of input gave the larger synaptic potential.

To ask whether selective reinnervation requires the integrity of the nerve sheaths spared by the crush lesions used in the experiments described above, I severed, rather than crushed, the sympathetic trunk between the 8 th and 9 th ganglia. When examined 9-12 weeks after denervation, in all 4 of these preparations, the innervation pattern closely resembled that seen in the crush preparations 6 or more weeks after denervation. Seventy-seven percent ( 20 of 24 ) of fast-B cells were appropriatcly reinnervated by $\mathrm{B}$ fibers, and $70 \%$ of $\mathrm{C}$ cells (35 of 50 ) were appropriately reinnervated by $C$ fibers. Eight percent ( 2 of 24) of the fast- $B$ cells received $C$ fiber input, and 16\% (8 of 50) of the $C$ cells received $B$ fiber input. Thus, most cells were appropriately reinnervated and relatively few were inappropriately reinnervated. Given this accuracy of reinnervation following nerve cut, it is unlikely that the reestablishment of appropriate synaptic connections depends primarily on axons growing through the old sheaths back to their original target cells.

The loss of B fiber synapses on C cells illustrated in Figure 5 (filled bars) could be due to a selective loss of inappropriate synapses; alternatively, it could be due to a random withdrawal of B fiber synapses from both fast-B cells and C cells. To distinguish between these possibilities, I have compared the mean numbers of $B$ fibers innervating cells of each class at various intervals after denervation. As shown in Figure 7, during the first several weeks both $B$ and $C$ cells acquired new inputs. During the period 6 or more weeks after denervation, the average number of $B$ fibers innervating the $C$ cells (inappropriate synapses) dropped markedly, eventually down to about onefitth of its peak value. On the other hand, the average number of B fiber inputs to fast-B cells (appropriate synapses) decreased less rapidly and to a lesser extent; even by the final time interval, four-fifths of the maximal number of innervating fibers were still detectable. Although there is an overall decrease in the number of B fibers innervating both types of neurons, the withdrawal of synapses does not appear to be random. Both the different time courses and the different magnitudes of withdrawal of synapses from the 2 cell classes indicate that synapse loss is selective, in that inappropriate $B$ fiber synapses on C cells are less likely to remain than appropriate synapses on B cells.

\section{Timing of reinnervation by $B$ and $C$ fibers}

That inappropriate inputs appear frequently on C cells, but only rarely on $B$ cells, suggests that the larger $B$ fibers may reinnervate the ganglia prior to the small $\mathrm{C}$ fibers, contacting not only their appropriate $\mathrm{B}$ cell targets but many $\mathrm{C}$ cells as well; it has indeed been reported that larger motor axons regenerate more rapidly than smaller ones (Schmidt and Stefani, 1976). In support of this hypothesis, ganglia examined during the first 2 weeks after denervation showed extensive reinnervation by $\mathrm{B}$ fibers but only sparse reinnervation by $C$ fibers. If the relative timing of return of the 2 preganglionic fiber groups determines which type of inappropriate synapses arises, it might be possible to generate more $\mathrm{C}$ fiber connections with $\mathrm{B}$ cells by giving $\mathrm{C}$ fibers an advantage in reinnervating ganglia. I tested this possibility by crushing the sympathetic trunk anterior to the 7 th ganglion in addition to the usual crush between the 8 th and 9 th ganglia (Lesion $1+$ Lesion 3 in Fig. 1). Thus, the $C$ fibers needed to grow a relatively short distance to the 9 th and 10th ganglia (2$3 \mathrm{~mm}$ to the $10 \mathrm{th}$ ), whereas the B fibers had several times as far to regenerate and, in addition, had to cross 2 lesion sites instead of one. In 7 preparations examined 3-9 weeks after such a double lesion, $18 \%$ (13 of 74) of fast-B cells rcccivcd synaptic input from $C$ fibers, markedly higher than the $2 \%$ observed after the single crush lesion described above. Most of these ganglia had not been reinnervated by B fibers; in a few the B fibers had returned and formed synapses with $B$ cells predominantly but also with some $C$ cells. These results indicate that the type of inappropriate connections ( $\mathrm{C}$ fiber $\rightarrow \mathrm{B}$ cell or $\mathrm{B}$ fiber $\rightarrow \mathrm{C}$ cell) that arises depends in part upon the sequence of return of the 2 preganglionic fiber groups. 
A

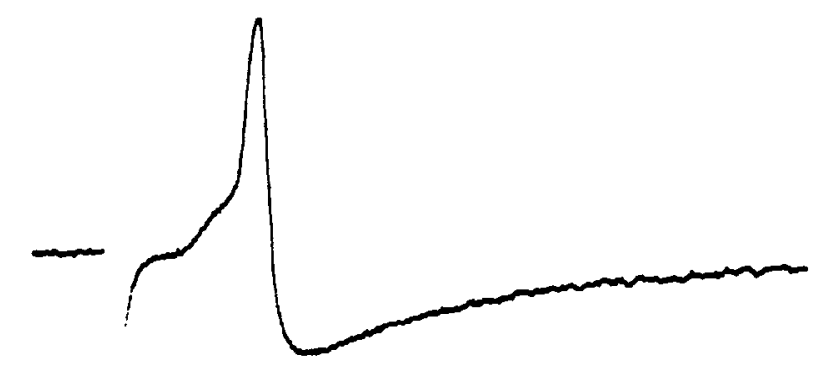

B

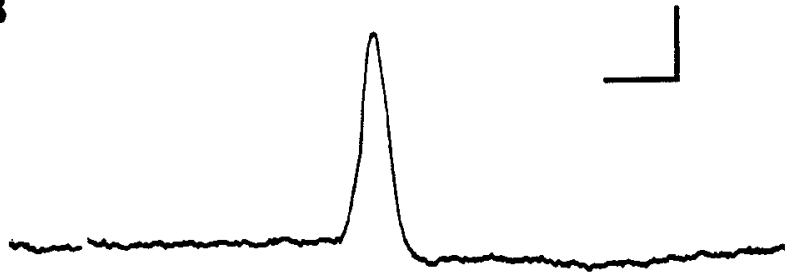

Figure 6. Physiological evidence of inappropriate synapses during reinnervation. Intracellular recordings from a $\mathrm{C}$ cell that received both appropriate and inappropriate synaptic input. $A$, Superthreshold synaptic input resulting from stimulation of the B fibers in the sympathetic trunk above the 7 th ganglion. $B$, Superthreshold synaptic potential resulting from stimulation of the $C$ fibers in the 8th nerve. Note the difference in latencies, which is typical for $B$ and $C$ fiber inputs, reflecting the difference in their respective conduction velocities. Calibration bars: horizontal, $10 \mathrm{msec}$; vertical, $20 \mathrm{mV}$. Action potentials retouched.

\section{Noncompetitive selectivity}

When $\mathrm{B}$ fibers reinnervate the ganglion before $\mathrm{C}$ fibers, it is of interest to know whether they form synapses randomly with $B$ and $\mathrm{C}$ cells or if they show some "preference" for appropriate connections with B cells. I therefore further retarded the return of $\mathrm{C}$ fibers by cutting the 7 th and 8 th communicating rami (Lesion 2 in Fig. 1), as well as crushing the trunk anterior to the 9th ganglion, thereby prolonging the period during which only $B$ fibers are available to ganglion cells. In 8 ganglia examined 1-3 weeks after this multiple lesion, $82 \%$ of the fast-B cells (64 of 78 ) but only $39 \%$ of the C cells ( 33 of 85 ) were reinnervated by $B$ fibers. Likewise, in the ganglia described in the preceding paragraph, in which the return of B fibers was retarded (Lesion $1+$ Lesion 3 ), the $C$ fibers preferentially reinnervated $C$ cells; although $18 \%$ of the fast-B cells (13 of 74) were reinnervated by $C$ fibers, $66 \%$ of the $C$ cells ( 45 of 68 ) received $C$ fiber input. These 2 sets of results thus indicate that from the outset, there is preferential reformation of appropriate connections, which occurs in the absence of competition between preganglionic fiber types.

\section{Competition between appropriate and inappropriate synapses}

In the first group of completely denervated ganglia described above (Lesion 1 only), I observed the appearance and eventual decline of inappropriate synaptic connections. The fact that inappropriate connections of $\mathrm{B}$ fibers began to decline only after appropriate $\mathrm{C}$ fiber input had returned to the majority of $\mathrm{C}$ cells (compare filled and open bars, Fig. 5) suggests that the elimination of inappropriate synapses results from some form of competition between synapses. Alternatively, B fiber inputs to

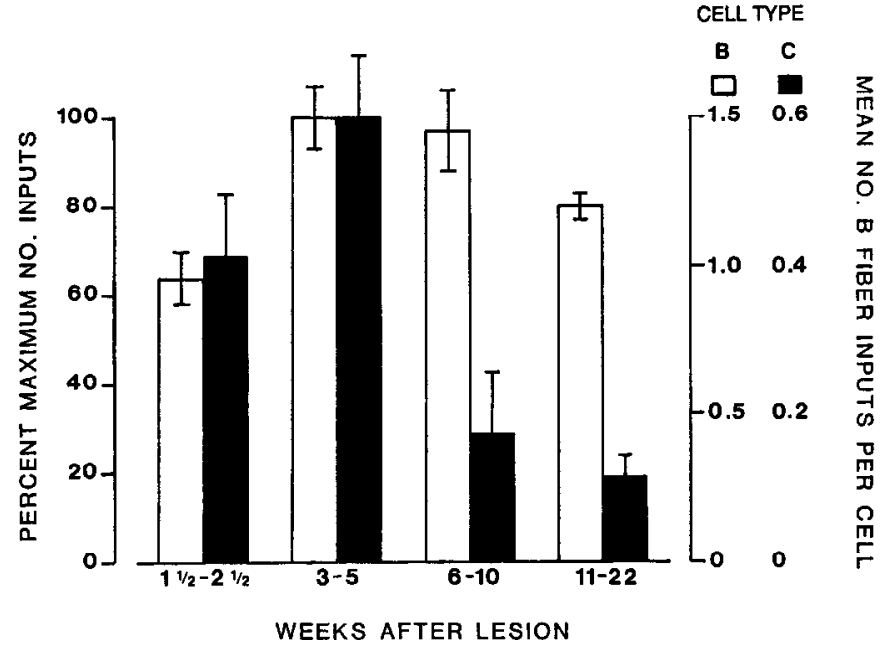

Figure 7. Selective loss of inappropriate synapses. The mean numbers of B fibers innervating C cells (open bars) and B fibers innervating $\mathrm{C}$ cells (filled bars) at various intervals after preganglionic lesion are compared. To facilitate comparison, the data are expressed as percentages (left-hand scale) of the maximal mean number of B fiber inputs observed in each cell class. Right-hand scales give the actual mean numbers of inputs for each cell class, showing the degree of scaling of the normalized data. The error bars represent standard errors $( \pm S E)$ of the values.

$\mathrm{C}$ cells might disappear spontaneously in the absence of competition from $\mathrm{C}$ fibers. To distinguish these possibilities, I prevented $\mathrm{C}$ fibers from reinnervating ganglia as described above (Lesion $1+$ Lesion 2) for 6-10 weeks. (This usually required resection of the entire 7 th and 8 th rami.) In this period of time, inappropriate $B$ fiber inputs to $C$ cells would have been reduced had $\mathrm{C}$ fibers been allowed to return (see Fig. 5, solid bars). However, in ganglia reinnervated by $B$ fibers alone, $65 \%$ of the $\mathrm{C}$ cells (54 of 83 ) retained inappropriate inputs (Fig. 5, shaded bar). Thus, the disappearance of $B$ fiber inputs to $C$ cells appears to be contingent upon the return of the normal $\mathrm{C}$ inputs, indicating that a competitive interaction is involved in elimination of inappropriate synaptic inputs.

Whereas $65 \%$ of $\mathrm{C}$ cells received $\mathrm{B}$ fiber input, all 29 fast-B cells studied in these ganglia received $B$ fiber input. This is a further indication of an inherent preference for appropriate synaptic connections, even in the absence of competition, as discussed above.

\section{Innervation of developing neurons in tadpoles}

The experiments described above show that during regeneration, or due to sprouting induced by partial denervation, neurons in the sympathetic nervous system of adult frogs may form inappropriate synaptic connections, which, through competitive interactions, tend to be eliminated in favor of appropriate connections. It is of interest to know whether similar mechanisms play a role in the formation of specific connections during normal embryonic development.

The methods used for determining the specificity of synapses in adult ganglia proved to be unsuitable for use in tadpole ganglia, since the neurons in the 9th ganglion of stage 17-18 tadpoles could not be readily identified by cell body size (see below) or antidromic conduction rate. In many neurons antidromic action potentials could not be recorded, either because the cells had not yet elaborated axons into the postganglionic nerve trunk, 


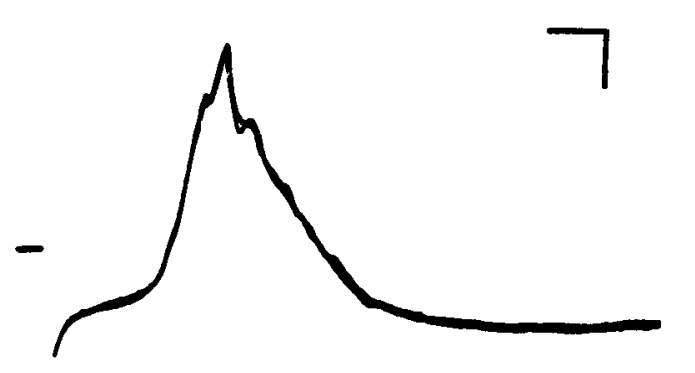

Figure 8. Antidromic compound action potential from the 9th ganglion of a stage 17 tadpole. Two traces are superimposed. The 9 th nerve was maximally stimulated approximately $3.5 \mathrm{~mm}$ away from the ganglion. No obvious division of postganglionic fibers into separate classes is apparent. Calibration bars: horizontal, $10 \mathrm{msec}$; vertical, $20 \mu \mathrm{V}$.

or action potentials could not propagate into the cell bodies, perhaps due to damage to the rami communicantes sustained during dissection. Nevertheless, in some preparations antidromic responses were observed in many cells. The latencies of these responses indicated that the axons of these cells conducted at rates well below $1 \mathrm{~m} / \mathrm{sec}$, with no indication of distribution into separate classes. Compound antidromic action potentials could not be resolved into components, as can be seen in Figure 8, which is a compound action potential recorded from the surface of the 9 th ganglion of a stage 17 tadpole, upon stimulation of the 9th nerve about $3.5 \mathrm{~mm}$ from the cell body (compare with Fig. 2). These conduction latencies suggest that $B$ cell axons have yet to become myelinated at stage 17 . Compound antidromic action potentials recorded from ganglia of stage 21-22 (metamorphic) tadpoles had complex waveforms (not shown), suggesting that by this period the conduction velocities of the $B$ and $C$ postganglionic axons have begun to diverge. Both extraand intracellular recordings from ganglia of postmetamorphic juvenile frogs showed that $B$ and $C$ populations are clearly distinguishable by the time metamorphosis is complete.

Further studies may reveal characteristics by which B and C cells may be distinguished in premetamorphic tadpoles, but for the present study I have addressed the question of synaptic specificity in tadpole ganglia by asking whether neurons can be found that are simultaneously innervated by both $B$ and $C$ fibers. If so, it may then be inferred that one (though it is not possible to say which) of the synaptic inputs is destined to be eliminated during maturation, since in the adult such simultaneous innervation is virtually never found.

One hundred thirteen neurons were studied in 15 preparations from stage 17-18 tadpoles. Input by only one type of preganglionic fiber could be demonstrated in the majority of neurons. These neurons received 1-3 presynaptic axons of the same type, as is found in adults. There was a preponderance of input due to B fibers; $67 \%$ of the cells ( 76 of 113 ) received $B$ fiber input exclusively, whereas only $15 \%$ (17 of 113 ) received $C$ fibers exclusively. Perhaps $\mathrm{C}$ fibers have not yet innervated many neurons by stages $17-18$, but sampling errors or damage during dissection to the delicate 7 th or 8 th rami communicantes carrying $C$ fibers might account for the apparent preponderance of $B$ fiber input.

In 13 of the 113 neurons, synaptic potentials could be evoked by both preganglionic $B$ and $C$ fiber pathways. In 5 of these 13 cells, it was clear that these potentials were due to different preganglionic fibers, since their amplitudes differed (see Fig. 9). In other cases, stimulation of either nerve trunk elicited re-

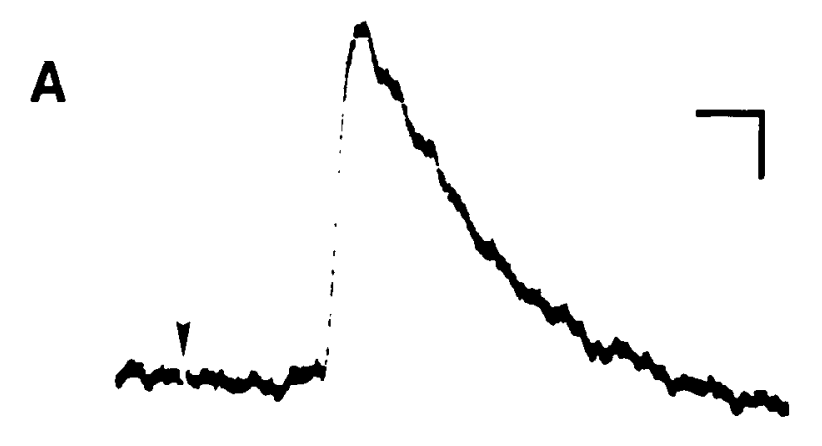

B

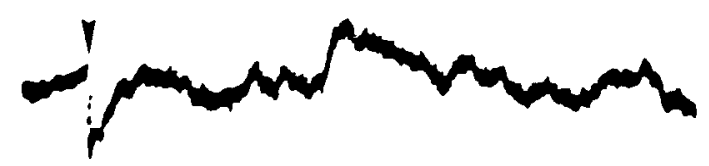

Figure 9. Physiological evidence of inappropriate synapses during embryonic development. This is an example of a tadpole neuron innervated by both $\mathrm{B}$ and $\mathrm{C}$ fibers. $A$, Response to stimulation of the $8 \mathrm{th}$ nerve. $B$, Response to stimulation of the sympathetic trunk anterior to the 6th ganglion. Arrowheads indicate the time at which the stimulus pulse was delivered. Calibration bars: horizontal, $10 \mathrm{msec}$; vertical, 2 $\mathrm{mV}$.

sponses that were not readily distinguishable, either because they were of similar amplitude or because the amplitudes of both fluctuated markedly. In 2 such instances, collateral branches of a single axon appeared to be present in both preganglionic trunks, since when stimuli to the 2 preganglionic pathways were delivered within a few milliseconds of each other, no synaptic potential appeared. In the remaining 3 of these instances, no such occlusion occurred, indicating that the 2 responses were due to different innervating fibers. Thus, of the 113 neurons studied, 8 were demonstrated by one of the above criteria to receive both $\mathrm{B}$ and $\mathrm{C}$ fiber input. Three additional cells with responses to stimulation of both preganglionic pathways were lost before a collision test could be performed.

The somatic diameters of those neurons that could be adequately visualized (90 of 113) were measured at the time of recording. Their diameters were unimodally distributed over a range between 14 and $38 \mu \mathrm{m}$, with $90 \%$ falling between 18 and $34 \mu \mathrm{m}$. There was essentially no difference in the size distributions of the subpopulations of neurons innervated exclusively by either B or C fibers (histograms not shown): The mean diameter of those cells innervated exclusively by B fibers was (in $\mu \mathrm{m}) 24.8 \pm 3.9(n=68)$, whereas that for those innervated exclusively by $C$ fibers was $23.4+5.6(n=12)$. Interestingly, those cells that were innervated by both $\mathrm{B}$ and $\mathrm{C}$ fibers tended to be among the largest cells: mean $32.1 \pm 7.2(n=7)$. Cells receiving multiple inputs of the same kind had diameters distributed throughout the size range.

Recordings were made from 24 neurons in 3 late-metamorphic tadpoles (stage 21-22), and no examples of simultaneous 
innervation by both B and C fibers were found, but with this small sample size infrequent simultaneous inputs might be missed. Recordings from ganglia of juvenile frogs (stage 25) indicate that by the time metamorphosis is complete, the neurons can be distinguished as $\mathrm{B}$ or $\mathrm{C}$ cells by their antidromic conduction velocities, and each neuron is innervated solely by appropriate preganglionic axons, just as is seen in adult animals. Thus, beforc the completion of metamorphosis, inappropriatc synapses have been eliminated, and the specific pattern of innervation found in mature ganglia has been established.

\section{Discussion}

Taken together, these experiments show that inappropriate synaptic connections in frog sympathetic ganglia may form under a variety of conditions, including sprouting induced by destroying one class of preganglionic axons, regeneration of new synapses following complete denervation, and during the normal course of development. In each case, these inappropriate connections are ultimately eliminated when both $B$ and $C$ preganglionic fibers are present, resulting in the highly specific pattern of innervation found in normal adult ganglia. In the experiments involving complete denervation of adult ganglia, for which the evidence is most complete, specificity of reinnervation appears to result from selective forces manifest in 2 ways: First, from the outset there is a preferential reformation of synapses of the appropriate type, although synapses may be made with inappropriate targets when these are available. Second, those inappropriate synapses that do arise are eliminated, apparently as a consequence of competitive interactions between appropriate and inappropriate fibers. The pattern of innervation found in tadpole ganglia suggests that similar mechanisms contribute to the formation of appropriate connections during development.

The sprouting of $C$ fibers to innervate $B$ cells observed after selective elimination of $\mathrm{B}$ fibers shows that the stimulus for sprouting, whatever its nature, is not specific for one or another type of preganglionic sympathetic fiber. The resulting $\mathrm{C}$ fiber $\rightarrow$ $B$ cell synapses are not found in normal ganglia, despite the close proximity of $\mathrm{C}$ fibers to $\mathrm{B}$ cells, which are frequently immediately adjacent to $C$ cells. No evidence is yet available to indicate the distance over which this sprouting may occur.

Sprouting was also indicated in partially denervated mammalian sympathetic ganglia (Murray and Thompson, 1957), but the behavioral methods used in those studies could not distinguish whether sprouts innervated new neurons (i.e., neurons they had not previously innervated prior to partial denervation) or whether the responding axons simply formed additional and more cffective connections with ncurons they already innervated (see Purves and Lichtman, 1978). A recent study (Maehlin and Njå, 1981) that used intracellular recording in addition to behavioral methods to reassess sprouting in partially denervated (albeit by a different means than that used by Murray and Thompson) mammalian ganglion suggests that sprouting fibers innervate mainly appropriate targets. Sprouting in the CNS is thought to be limited to axons that form part of the normal afferent innervation of areas partially denervated (Cotman and Lynch, 1976). In frog sympathetic ganglia, sprouting can clearly produce synapses between foreign partners.

When the cut B fibers regenerate, they form synapses exclusively with B cells and the sprouted synapses are no longer detectable electrophysiologically. Presumably the sprouted synapses are lost as a consequence of a competitive interaction between regenerating $B$ fibers and sprouted $C$ fibers, the basis of which is not known, however. $C$ fibers may have a competitive disadvantage because they make synapses with many $B$ cells in addition to their normal connections with $C$ cells, and they are thus "overextended" (Purves, 1976). Perhaps the synapses most readily lost under such circumstances are the recently formed, and perhaps less well-established, sprouted ones. An alternative explanation for the loss of sprouted synapses is that thcy are somchow inappropriate for the B cells and are recognized as such by either the pre- or postsynaptic neurons. Such inappropriate synapses might be lost when preferred inputs from B fibers become available. These alternatives were suggested as possible explanations for the loss of anomalous sprouted synapses between cardiac ganglion neurons upon return of normal preganglionic input in frog parasympathetic ganglia (Sargent and Dennis, 1981). Although the present sprouting experiments do not distinguish between these alternatives, the experiments described here involving reinnervation of completely denervated ganglia indicate that appropriateness of competing synapses plays a major role in determining which synapses will be maintained.

The anomalous synapses produced in response to partial denervation arise rapidly and can be unequivocally distinguished from normal synapses for study with intracellular physiological recording. The frog sympathetic ganglion is thus a convenient model system for studying the phenomena of sprouting and competitive synapse elimination. These phenomena have been exploited recently in a study revealing the influence of preganglionic innervation on properties of postsynaptic receptors in ganglion cells (Marshall, 1985).

\section{The relative nature of synaptic specificity}

The complete denervation experiments shed more light on the question of whether neurons can distinguish between appropriate and inappropriate synaptic partners. The use of selective lesions permitted the return of either $\mathrm{B}$ fibers or $\mathrm{C}$ fibers alone. When only one class of preganglionic fibers reinnervates the ganglion, synapses with appropriate targets (B fiber $\rightarrow$ B cell or $C$ fiber $\rightarrow C$ cell) are found more often than connections with inappropriate targets (B fiber $\rightarrow \mathrm{C}$ cell or $\mathrm{C}$ fiber $\rightarrow \mathrm{B}$ cell). This indicates that there is an overall preference for appropriate connections that is expressed in the absence of competition between different classes of preganglionic fibers. That this is not simply due to the relative numbers of B and C cells in the ganglia is shown by the fact that "preference" is demonstrated for both $\mathrm{B}$ fiber $\rightarrow \mathrm{B}$ cell and $\mathrm{C}$ fiber $\rightarrow \mathrm{C}$ cell connections.

Several bases for this initial preference may be postulated. One possibility is that axons may be mechanically guided back to former synaptic sites through individual channels bounded by connective tissue and glial cells. Such channels might survive the crush lesions used in most of these experiments. Another possibility is that regenerating axons actively distinguish and follow chemically specific substrate pathways back to their former targets. Alternatively, such guidance mechanisms might serve only to bring axons to the general vicinity of ganglion cells, with the preferential formation of appropriate connections resulting from recognition between axons and ganglion cells, perhaps by selective affinity for each other (Sperry, 1963). In considering the role of guidance mechanisms in the establishment of appropriate connections, account must be taken that $B$ and $C$ cells are interspersed throughout the ganglion. It appears unlikely that axons are confined to a rigid network guiding particular axons to particular cells, as shown here by the experiments in which intact $\mathrm{C}$ fibers were induced to sprout and form func- 
tional synapses with $\mathrm{B}$ cells denervated by transection of the $\mathrm{B}$ fibers; no barrier prevents the sprouting fibers from forming synapses with B cells. The early formation of many inappropriate synapses in the present experiments further argues against a rigid guidance mechanism; it also argues against an exclusive, inviolable form of cell recognition.

These results are consistent with those of various cross-innervation studies which indicate that autonomic neurons in mammals and amphibians may be innervated by a variety of foreign cholinergic axons (McLachlan, 1974; Purves, 1976; Sargent and Dennis, 1977; Proctor et al., 1979; Proctor and Roper, 1982). Despite the overall preference for appropriate innervation discussed above, the present experiments show that in the absence of a "preferred" synaptic partner, a ganglion cell may receive innervation from an inappropriate preganglionic axon. Furthermore, if the preferred input is kept away, the inappropriate connection is maintained, and not eliminated spontaneously.

Of particular interest here is the finding that when the preferred axons do return, inappropriate inputs already present tend to be lost in favor of appropriate ones, apparently as a consequence of some form of competition. Also interesting is the observation that although the returning $C$ fibers will synapse with $\mathrm{C}$ cells previously reinnervated by $\mathrm{B}$ fibers, these same $\mathrm{C}$ fibers will only rarely synapse with $B$ cells previously reinnervated by the appropriate B fibers. This suggests that the presence of an appropriate connection discourages the formation of an inappropriate one, whereas an inappropriate connection does not discourage the formation of an appropriate one. These results imply that specificity of neuronal connections may be relative-synapses arc sclected on the basis of an order of preference.

Through a competitive interaction that is not understood, the preferred synapses are retained and the inappropriate ones are eliminated, as judged by physiological criteria. $\mathrm{B}$ fiber $\rightarrow \mathrm{C}$ cell synapses may be lost because the pre- or postganglionic neurons recognize these connections as inappropriate. However, "inappropriateness" per se need not be the reason for their loss; it may be that the $B$ fibers, having reinnervated not only most of the B cells, but many C cells as well, are "overextended" and make more synapses than their metabolic machinery can ultimately maintain. Under such circumstances, some of the synapses must be lost (although they are maintained for at least 10 weeks when $C$ fibers are kept away). The results show (see Fig. 7) that synapses made by $B$ fibers are not lost randomly; it is mainly those made with $\mathrm{C}$ cells that are eliminated. Whatever the primary cause of this elimination, there clearly must be something that distinguishes inappropriate synapses from appropriate ones; synapse loss is selective.

This finding has an important implication for the significance of the phenomenon known as "synapse elimination." This term has been applied to the observation that in developing animals, various neural targets (see Purves and Lichtman, 1980, for review) receive functional innervation from more axons than they normally receive in adults, and each innervating axon contacts a larger complement of target cells than it ultimately will at maturity. Purves and Lichtman have suggested that this process may serve to regulate the number and distribution of synapses made within a target. In addition to this well-documented, essentially quantitative role, synapse elimination may serve a qualitative role in neuronal specificity. The findings in frog sympathetic ganglia presented here support such a role by showing that during regeneration, and perhaps during development, some degree of imprecision of initial synaptic contacts can be corrected by the selective elimination of inappropriate synapses.

These findings are consistent with a modified form of Sperry's (1963) chemoaffinity hypothesis, in which neurons recognize each other by means of a family of surface molecules. Appropriateness of connection is determined in a relative, rather than in an absolute manner. Thus, if a preferred synaptic connection is not possible, a less preferred connection is acceptable, and better than no connection at all. Cells may have a hierarchy of preferences as to which axons they will make connections with. Conversely, the incoming axons may have a range of affinities for potential target neurons. The selectivity may be exerted by either the pre- or postganglionic cell, or both.

Whatever the cellular and molecular mechanisms giving rise to selectivity, their purpose is to properly wire the nervous system as a substrate for integrated behavior. What criteria constitute "proper" wiring? Studies of reinnervation of mammalian sympathetic ganglia (Njå and Purves, 1977b, 1978) and the present study of the amphibian preparation reveal different, and presumably complementary, aspects of the nature of selectivity. In mammals, selectivity appears to have a positional basis, such that preganglionic axons derived from different segmental levels of the spinal cord tend to reinnervate a subset of ganglion cells whose peripheral targets, though of several functional types, share a restricted location on the body. Thus, one basis for selectivity is to match ganglionic neurons serving a particular region of the body with preganglionic neurons concerned with the regulation of that body region. A second basis for selectivity would be to match ganglion cells of different functional classes with appropriate preganglionic input mediating particular physiological functions. Functional selectivity is difficult to assess at the cellular level in mammalian ganglia and, accordingly, has not been well documented there, though it presumably exists (see Purves and Lichtman, 1978). On the other hand, in frog sympathetic ganglia the presence of 2 readily distinguishable classes of ganglion cells and their distinct sources of preganglionic inputs facilitates the assessment of selectivity by a functional criterion. Indeed, the reinnervation of $B$ and $C$ cells by their appropriate classes of preganglionic neurons establishes that regenerating synapses follow selective rules based in part on the restoration of proper functional circuitry.

\section{Selective reinnervation in other systems}

Landmesser and Pilar (1970) reported that 2 neuronal populations in the pigeon parasympathetic ciliary ganglion were reinnervated by appropriate preganglionic axons following section and regeneration of the oculomotor nerve. Their technique of recording postganglionic compound action potentials would not have revealed transient inappropriate connections if they generated subthreshold postsynaptic potentials, and it might not have detected superthreshold connections if they were relatively infrequent.

Selective reinnervation of neurons also occurs in mammalian sympathetic ganglia (Langley, 1897; Guth and Bernstein, 1961; Njå and Purves, $1977 \mathrm{a}, \mathrm{b}$ ). However, in the guinea pig, $\mathrm{Njå} \mathrm{and}$ Purves were unable to find evidence for formation of inappropriate connections, even early in reinnervation ( $\mathrm{Njå}$ and Purves, 1978). The discrepancy between their results and my own could be due to a more effective early selection of preferred connections in guinea pigs than in frogs or to a faster elimination of incorrect contacts in the warm-blooded animals. The innerva- 
tion of mammalian ganglion cells is considerably more complex than that of frog ganglia, and the methods for assessing specificity are less direct, so if a transient period of imprecise innervation exists in the mammal, it might escape detection. The simplicity and manipulability of innervation in frogs, the direct manner in which an inappropriate connection may be recognized, and a presumably slower rate of synaptic remodeling in the cold-blooded frog, have facilitated the resolution of 2 distinct processes that underlie selective reinnervation.

The formation and subsequent suppression of 2 different types of abnormal synaptic input to parasympathetic ganglion cells in the frog heart have been reported. Abnormal synapses between the ganglion cells (Sargent and Dennis, 1981) and synapses by hypoglossal motorneurons onto ganglion cells (Proctor et al., 1979, Proctor and Roper, 1982) are both suppressed when the normal vagal preganglionic axons reinnervate the heart and restore synaptic function. In both cases, the abnormal synaptic inputs persist if the normal innervation is kept away, indicating that in this system as well synaptic competition plays a role in the restoration of normal connections.

The specificity of reinnervation of skeletal muscle has been extensively studied in amphibians and mammals. Amphibia are capable of selective reinnervation of distinct myofiber types within individual skeletal muscles (Hoh, 1971; Schmidt and Stefani, 1976) and appropriate reinnervation of whole muscles by matching motor nerves (Grimm, 1971). Furthermore, in amphibian muscles, previously formed inappropriate synapses may be eliminated upon return of the normal innervation (Schmidt and Stefani, 1976; Dennis and Yip, 1978). In contrast, in mature mammals selective reinnervation of skeletal muscle does not occur (Bcrnstcin and Guth, 1961; Miledi and Stefani, 1969; Frank et al., 1975; but see Wigston and Sanes, 1982). Dennis and Yip (1978) propose that these differences between amphibians and mammals might reflect the retention of some embryonic characteristics by adult neurons in the more primitive species. Whatever the reasons, regeneration of appropriate neuronal connections in mammals has so far been convincingly demonstrated only in the autonomic nervous system.

\section{Implications for development}

The formation of inappropriate synapses and their eventual elimination in favor of appropriate ones may also occur during development of the nervous system. In stage 17-18 tadpoles, at least $7 \%$ of the neurons recorded from had synaptic inputs that were destined to be lost during metamorphosis. This is perhaps a lower limit on the fraction of neurons that are transiently inncrvated by inappropriate axons, for the following reasons: If $\mathrm{C}$ fibers were damaged during dissection of some of the preparations (the 7 th and 8 th rami communicantes were tenuous compared with the sympathetic trunk), the number of neurons with simultaneous $B$ and $C$ fiber innervation might be underestimated because some might be left apparently receiving only $B$ fiber input. It is also possible that some of the neurons innervated by only one type of preganglionic axon are actually innervated inappropriately, having yet to be innervated by appropriate axons; without a means of distinguishing $B$ and $C$, cells, it is impossible to say to what extent this may be true. A recent report (Horn et al., 1987) indicates that C cells comprise slightly more than half of the neurons in the 9 th and 10th ganglia of adult bullfrogs. In light of that finding, the predominant innervation of sampled tadpole neurons by $B$ fibers $(67 \%)$ and sparse innervation by $C$ fibers $(15 \%)$ in the present study might support the view that many of these neurons were actually destined to be $C$ cells with $C$ fiber input, and indeed inappropriately innervated by $B$ fibers. The possibility that unknown sampling errors might account for the apparent predominant B fiber innervation is certainly not ruled out. Perhaps a probe, such as neuropeptide $Y$ immunoreactivity (Horn et al., 1987), specific for one or another ganglion cell type can be of help in addressing this question.

On the other hand, the apparent innervation of most cells by one type of preganglionic fiber suggests that $B$ and $C$ fibers innervate predominantly nonoverlapping subsets of sympathetic ganglion cells, at least at stages $17-18$. A reasonable hypothesis is that most of these connections are appropriate; perhaps this suggests an overall tendency for appropriate synapse formation from the outset, in analogy to the noncompetitive "preference" observed during regeneration after complete denervation in adult frogs. The existence of some inappropriate synapses might then be viewed as a consequence of an exploratory process vital to the search for appropriate synaptic partners.

There is considerable evidence that patterns of innervation are both quantitatively and qualitatively modified during development. Besides the quantitative changes of so-called "synapse elimination" already mentioned, the segmental organization of neuromuscular connections in amphibians and birds appears less precise in embryos than in adults (Lamb, 1976; Pettigrew et al., 1979). Studies in a variety of regions within the CNS (see Chap. 12, Purves and Lichtman, 1985, for review) indicate that immature neurons project to targets beyond those they will innervate in the adult animal. In at least one case (So et al., 1978) the retraction of an inappropriate projection appears contingent upon the arrival of the appropriate afferent axons.

It may be that the regeneration of connections in frog ganglia recapitulates a sequence of events that takes place during development. Although regeneration is not completely analogous, the restoration of a more-or-less normal pattern of connections suggests that some of the mechanisms that contribute to the specificity of synapse formation during development are retained in the adult frog.

\section{References}

Bernstein, J. J., and L. Guth (1961) Nonselectivity in establishment of neuromuscular connections following nerve regeneration in the rat. Exp. Neurol. 4: 262-275.

Brown, K. T., and D. G. Flaming (1977) New microelectrode techniques for intracellular work in small cells. Neuroscience 2: 813-827.

Cotman, C. W., and G. S. Lynch (1976) Reactive synaptogenesis in the adult nervous system. In Neuronal Recognition, S. Barondes, ed., Plenum, New York.

Dennis, M. J., and J. W. Yip (1978) Formation and elimination of foreign synapses on adult salamander muscle. J. Physiol. (Lond.) 274: 299-310.

Dodd, J., and J. P. Horn (1983) A reclassification of B and C neurons in the ninth and tenth paravertebral sympathetic ganglia of the bullfrog. J. Physiol. (Lond.) 334: 255-269.

Dunn, P. M., and L. M. Marshall (1983) Appearance of acetylcholine chemosensitivity during synaptogenesis in frog sympathetic ganglia. Soc. Neurosci. Abstr. 9: 689.

Feldman, D. H. (1979) Specificity of reinnervation of frog sympathetic ganglia. Soc. Neurosci. Abstr. 5: 625.

Feldman, D. H. (1980) Synaptic competition and sprouting in frog sympathetic ganglia. Soc. Neurosci. Abstr. 6: 410.

Francini, F., and F. Urbani (1973) Organization of the efferent extraspinal pathways in Rana esculenta. Arch. Fisiol. 70: 149-165.

Frank, E., J. K. S. Jansen, T. Lomo, and R. H. Westgaard (1975) The 
interaction between foreign and original motor nerves innervating the soleus muscle of rats. J. Physiol. (Lond.) 247: 725-743.

Gaupp, E. (1899) Ecker's und Wiedersheim's Anatomie des Frosches: II. S. 214, F. Vieweg, Braunschweig.

Grimm, L. (1971) An evaluation of myotypic respecification in axolotls. J. Exp. Zool. 178: 479-496.

Guth, L., and J. J. Bernstein (1961) Selectivity in the re-establishment of synapses in the superior cervical ganglion of the cat. Exp. Neurol. 4: $59-69$.

Hoh, J. F. Y. (1971) Selective reinnervation of fast-twitch and slowgraded muscle fibers in the toad. Exp. Neurol. 30: 263-276.

Horn, J. P., W. D. Stofer, and S. Fatherazi (1987) Neuropeptide Y-like immunoreactivity in bullfrog sympathetic ganglia is restricted to $\mathrm{C}$ cells. J. Neurosci. 7: 1717-1727.

Kuba, K., and K. Koketsu (1978) Synaptic events in sympathetic ganglia. Prog. Neurobiol. 11: 79-169.

Lamb, A. H. (1976) The projection patterns of the ventral horn to the hindlimb during development. Dev. Biol. 54: 82-99.

Landmesser, L., and G. Pilar (1970) Selective reinnervation of two cell populations in the adult pigeon ciliary ganglion. J. Physiol. (Lond.) 220: $243-256$

Langley, J. N. (1897) On the regeneration of preganglionic and of postganglionic nerve fibres. J. Physiol. (Lond.) 22: 215-230.

Libet, B., S. Chichibu, and T. Tosaka (1968) Slow synaptic responses and excitability in sympathetic ganglia of the frog. J. Neurophysiol. 31: 383-395.

Maehlen, J., and A. Njå (1981) Selective synapse formation during sprouting and after partial denervation of the guinea-pig superior cervical ganglion. J. Physiol. (Lond.) 319: 555-567.

Marshall, L. M. (1985) Presynaptic control of synaptic channel kinetics in sympathetic neurons. Nature 317: 621-623.

McLachlan, E. M. (1974) The formation of synapses in mammalian sympathetic ganglia reinnervated with preganglionic or somatic nerves. J. Physiol. (Lond.) 237: 217-242.

Miledi, R., and E. Stefani (1969) Non-selective reinnervation of slow and fast muscle fibers in the rat. Nature 222: 569-571.

Murray, J. C., and J. W. Thompson (1957) The occurrence and function of collateral sprouting in the sympathetic nervous system of the cat. J. Physiol. (Lond.) 135: 133-162.

Nishi, S., H. Soeda, and K. Koketsu (1965) Studies on sympathetic $\mathrm{B}$ and $\mathrm{C}$ neurons and patterns of preganglionic innervation. J. Cell. Comp. Physiol. 66: 19-32.

Njå, A., and D. Purves (1977a) Specific innervation of guinea-pig superior cervical ganglion cells by preganglionic fibers arising from different levels of the spinal cord. J. Physiol. (Lond.) 264: 563-583.

Njâ, A., and D. Purves (1977b) Reinnervation of guinea-pig superior cervical ganglion cells by preganglionic fibers arising from different levels of the spinal cord. J. Physiol. (Lond.) 272: 633-651.
Njå, A., and D. Purves (1978) Specificity of initial synaptic contacts made on guinea-pig superior cervical ganglion cells during regeneration of the superior cervical trunk. J. Physiol. (Lond.) 281: 45-62.

Pettigrew, A. G., R. Lindeman, and M. R. Bennett (1979) Development of the segmental innervation of the forelimb. J. Embryol. Exp. Morphol. 49: 115-137.

Proctor, W., and S. Roper (1982) Competitive elimination of foreign motor innervation on autonomic neurons in the frog heart. J. Physiol. (Lond.) 326: 189-200.

Proctor, W., S. Frenk, B. Taylor, and S. Roper (1979) 'Hybrid' synapses formed by foreign innervation of parasympathetic neurons: A model for selectivity during competitive reinnervation. Proc. Natl. Acad. Sci. USA 76: 4695-4699.

Purves, D. (1975) Functional and structural changes in sympathetic neurons following interruption of their axons. J. Physiol. (Lond.) 252: 429-463.

Purves, D. (1976) Competitive and non-competitive reinnervation of mammalian sympathetic neurons by native and foreign fibers. J. Physiol. (Lond.) 261: 453-475.

Purves, D., and J. W. Lichtman (1978) The formation and maintenance of synaptic connections in autonomic ganglia. Physiol. Rev. 58: 821-862.

Purves, D., and J. W. Lichtman (1980) Elimination of synapses in the developing nervous system. Science 210: 153-157.

Purves, D., and J. W. Lichtman (1985) Principles of Neural Development, Sinauer, Sunderland, MA.

Sargent, P. B., and M. J. Dennis (1977) Formation of synapses between parasympathetic neurons deprived of preganglionic innervation. $\mathrm{Na}$ ture 268: 456-458.

Sargent, P. B., and M. J. Dennis (1981) The influence of normal innervation upon abnormal synaptic connections between frog parasympathetic neurons. Dev. Biol. 81: 65-73.

Schmidt, H., and E. Stefani (1976) Reinnervation of twitch and slow muscle fibers of the frog after crushing the motor nerves. J. Physiol. (Lond.) 258: 99-123.

Skok, V. I. (1965) Conduction in tenth ganglion of the frog sympathetic trunk. Fed. Proc. (Tranl. Suppl.) 24: T363-T367.

So, K. F., G. E. Schneider, and D. O. Frost (1978) Posinatal development of retinal projections to the lateral geniculate body in Syrian hamsters. Brain Res. 142: 343-352.

Sperry, R. W. (1963) Chemoaffinity in the orderly growth of nerve fiber patterns and connections. Proc. Natl. Acad. Sci. USA 50: 703710.

Taylor, A. C., and J. J. Kollros (1946) Stages in the normal development of Rana pipiens larvae. Anat. Rec. 94: 7-25.

Wigston, D. I., and J. R. Sanes (1982) Selective reinnervation of adult mammalian muscle by axons from different segmental levels. Nature 299: 466-467. 